OPEN ACCESS

Edited by:

Petros Karakousis,

Johns Hopkins University,

United States

Reviewed by:

Silvia Sánchez-Ramón,

Complutense University of Madrid,

Spain

Jose Luis Subiza,

Inmunotek Alergia e Inmunología,

Spain

*Correspondence:

Markus Maeurer

markus.maeurer@

fundacaochampalimaud.pt

Specialty section:

This article was submitted to

Infectious Diseases,

a section of the journal

Frontiers in Microbiology

Received: 28 June 2019

Accepted: 04 December 2019

Published: 10 January 2020

Citation:

Lérias JR, de Sousa E,

Paraschoudi G, Martins J,

Condeço C, Figueiredo N,

Carvalho C, Dodoo E, Maia A,

Castillo-Martin M, Beltrán A,

Ligeiro D, Rao M, Zumla $A$ and

Maeurer M (2020) Trained Immunity

for Personalized Cancer

Immunotherapy: Current Knowledge

and Future Opportunities.

Front. Microbiol. 10:2924.

doi: 10.3389/fmicb.2019.02924

\section{Trained Immunity for Personalized Cancer Immunotherapy: Current Knowledge and Future Opportunities}

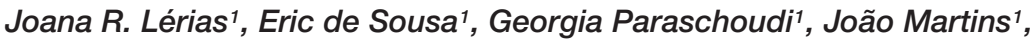 \\ Carolina Condeço ${ }^{1}$, Nuno Figueiredo², Carlos Carvalho' ${ }^{2}$, Ernest Dodoo', Andreia Maia ${ }^{3}$, \\ Mireia Castillo-Martin 3,4, Antonio Beltrán ${ }^{4}$, Dário Ligeiro5, Martin Rao, \\ Alimuddin Zumla ${ }^{6}$ and Markus Maeurer ${ }^{1 *}$
}

\begin{abstract}
${ }^{1}$ ImmunoSurgery Unit, Champalimaud Centre for the Unknown, Lisbon, Portugal, ${ }^{2}$ Digestive Unit, Champalimaud Clinical Centre, Lisbon, Portugal, ${ }^{3}$ Molecular and Experimental Pathology Laboratory, Champalimaud Centre for the Unknown, Lisbon, Portugal, ${ }^{4}$ Department of Pathology, Champalimaud Clinical Centre, Lisbon, Portugal, ${ }^{5}$ Lisbon Centre for Blood and Transplantation, Instituto Português do Sangue e Transplantação, Lisbon, Portugal, ${ }^{6}$ Division of Infection and Immunity, NIHR Biomedical Research Centre, UCL Hospitals, NHS Foundation Trust, University College London, London,

United Kingdom
\end{abstract}

Memory formation, guided by microbial ligands, has been reported for innate immune cells. Epigenetic imprinting plays an important role herein, involving histone modification after pathogen-/danger-associated molecular patterns (PAMPs/DAMPs) recognition by pattern recognition receptors (PRRs). Such "trained immunity" affects not only the nominal target pathogen, yet also non-related targets that may be encountered later in life. The concept of trained innate immunity warrants further exploration in cancer and how these insights can be implemented in immunotherapeutic approaches. In this review, we discuss our current understanding of innate immune memory and we reference new findings in this field, highlighting the observations of trained immunity in monocytic and natural killer cells. We also provide a brief overview of trained immunity in non-immune cells, such as stromal cells and fibroblasts. Finally, we present possible strategies based on trained innate immunity that may help to devise host-directed immunotherapies focusing on cancer, with possible extension to infectious diseases.

Keywords: trained immunity, macrophages, dendritic cells, inflammation, cancer, pathogens, immune responses, immunotherapy

\section{BACKGROUND}

Monocytic cells including macrophages and dendritic cells (DCs), granulocytes and natural killer (NK) cells, which feature a spectrum of innate immune cells, constitute the quintessential first line of host innate immune defense and appear to undergo epigenetic reprograming during an antimicrobial immune response (Nakayama et al., 2011; Abbas et al., 2014; Saeed et al., 2014; Vono et al., 2017). The permanent polarization of certain subsets of these cells triggered by pathogen-driven inflammation - leads to the development of molecular signatures forming an "immunological matrix." This "trained immunity" does not resemble immunological memory of adaptive immune cells, i.e., $\mathrm{T}$ and $\mathrm{B}$ cells, but rather pre-programing of cells that will respond with similar effector molecules to subsequent challenge driven by recognition of 
pathogen-/danger-associated molecular patterns (PAMPs/ DAMPs) by pathogen-recognition receptors (PRRs), such as Toll-like receptors (TLRs) (Gourbal et al., 2018). Stromaassociated mesenchymal stromal cells (MSC) and fibroblasts, which can also harbor pathogens (Das et al., 2013; McCormack et al., 2013; Beamer et al., 2014; Khan et al., 2017), are equipped with the capacity to present antigens to $\mathrm{T}$ cells via the human leukocyte antigen (HLA) class I and class II pathways during inflammation (Ilangumaran et al., 2002; Romieu-Mourez et al., 2007; Morandi et al., 2008; Das et al., 2013; Crowley et al., 2018; Hamada et al., 2019), and have been discussed to possess trained immunity characteristics (Hamada et al., 2019).

There are several examples of the clinical use of attenuated microorganisms in immunotherapy, such as the attenuated Mycobacterium bovis Bacille Calmette-Guerín (BCG) strain as an adjuvant for treatment of non-muscle-invasive bladder cancer (Pettenati and Ingersoll, 2018). BCG induces upregulation of cytokine production, e.g., granulocyte-macrophage colonystimulating factor (GM-CSF), interleukin-15, tumor-necrosis factor (TNF), expression of MHC class II on urothelial cells and activation of APCs associated with clinically relevant host responses (Ikeda et al., 2002; Mitropoulos, 2005; Bisiaux et al., 2009; Pettenati and Ingersoll, 2018). Clinical studies in Guinea-Bissau have shown that the tuberculosis (TB) vaccine BCG induces cross-protective immune responses among infants in low-resource settings concomitant with a high level of exposure to different infectious agents (Jensen et al., 2015). This is clinically significant, since exposure to a variety of infectious agents early in life in countries with high pathogen transmission rates has been postulated to protect against immunological diseases later in adulthood (MacGillivray and Kollmann, 2014), with a crucial role for PAMP-driven shaping of innate immune responses. Further to the unmistakable role of adaptive immunological memory in immunity, the role of trained immunity in innate immune cells demands attention. In line with this, BCG-primed hematopoietic stem cells (HSCs) - which gave rise to epigenetically modified macrophages - were shown to induce superior recall responses against virulent Mycobacterium tuberculosis (Mtb) challenge in a mouse model (Kaufmann et al., 2018). Inflammation and HSC plasticity as well as development is similar to immuno-physiological processes occurring in the bone marrow during disease, i.e., TNF- $\alpha$ and IFN- $\alpha$ upregulation and HSC differentiation, G-CSF and IL-1 $\beta$ expression leading to HSC proliferation (Pietras, 2017).

Trained innate immunity may in part be responsible for local fine-tuning and immunomodulation within the bone marrow (and other tissue compartments), where long-term memory T-cell populations can be found in healthy adults (Okhrimenko et al., 2014). Alternatively, initial stimulation of myeloid cells by fungal cell wall-derived $\beta$-glucan has been shown to promote superior control of subsequent infection with bacterial pathogens (Quintin et al., 2012; Arts et al., 2018a; Rusek et al., 2018). The role of trained immunity in the context of immunomodulation in cancer was also recently reviewed (Netea et al., 2017), expanding the biological relevance of trained immunity. In this review/viewpoint, we summarize known information concerning trained immunity and discuss relevant observations in view of personalized cancer immunotherapy, particularly on adaptive T-cell responses directed against cancer cells.

\section{INNATE IMMUNE CELLS AND IMMUNOLOGICAL MEMORY}

\section{Macrophages and Dendritic Cells}

Priming of human monocytes and monocyte-derived macrophages with LPS, an integral component of bacterial endotoxin (TLR4 ligand), or zymosan, a polysaccharide which belongs to the fungal cell wall (TLR2 and Dectin-1 ligand), has been shown to be cross-reactive (LPS- or -zymosan-primed monocytes can react to either stimulus), albeit with a dependence of the dose of the stimulus (Madej et al., 2017). Importantly, IL- $1 \beta$ production by macrophages initially primed by LPS or Escherichia coli is markedly reduced following re-exposure, although in monocytes re-exposure to E. coli, but not LPS, produced much higher amounts of IL-1 $\beta$ (Madej et al., 2017). This observation strongly hinted at the exposure of monocytic cells to one type of pathogen affording immune reactivity to another, i.e., bacteria vs. fungi. The immune tolerance induced by LPS could, in part, explain T-cell dysfunction in sepsis syndrome - which is reversible by exogenous IL-7 administration in patients (Francois et al., 2018). A study in mice showed that trained immunity in DC driven by protective vaccination against Cryptococcus neoformans, an opportunistic fungal pathogen of the lungs (Kanjanapradit et al., 2017), allowed the trained DCs to generate stronger pro-inflammatory responses against bacterial pathogens in vitro, suggesting an effect of trained immunity (Hole et al., 2019).

There is also evidence of Plasmodium falciparum (Pf)-induced trained immunity in adherent cells from peripheral blood mononuclear cells (PBMCs) - most likely macrophages - which undergo $\mathrm{H} 3 \mathrm{~K} 4$ trimethylation leading to their subsequent ability to produce high amounts of IL- 6 an TNF- $\alpha$ in response to TLR1/2 stimulation with Pam3CSK4 in a manner dependent on hemozoin or Pf-infected erythrocytes (Schrum et al., 2018). TLR1 and 2 recognize peptidoglycan, a quintessential component of the bacterial cell wall, and can engage NF- $\kappa \mathrm{B}$ activation for pro-inflammatory cytokine signaling, as shown in the context of antimycobacterial immune responses (Takeuchi et al., 2002). As such, TLR1/2-sensisitized macrophages may have a role in the interaction with bacterial pathogens and possibly promote their clearance.

Studies have shown that oxidized low-density lipoprotein particle (oxLDL)- or $\beta$-glucan-stimulated macrophages shift to the glycolytic pathway, which promotes polarization to an inflammatory M1 phenotype and induces expression of proinflammatory cytokines, such as IL-1 $\beta$ and TNF- $\alpha$, among others (Biswas, 2015; Groh et al., 2017). Both cytokines have pro- as well as anti-tumor properties in cancer immunology, i.e., priming of T-cell responses and tumor elimination vs. induction of chronic, cancerogenic inflammation (Maeurer et al., 1996; Balkwill, 2009; Gross et al., 2017; Bent et al., 2018; Mantovani et al., 2018). Simultaneously, accumulation of lipids 
in trained macrophages has been linked to the pathogenesis of atherosclerosis (Groh et al., 2017), raising the question of how much fatty acid metabolism is allowable before it contributes to a different pathology. The shift to aerobic glycolysis in cancer cells fuels their uncontrolled growth, while lactate appears to favor disease dissemination (Jiang, 2017), both of which have also been noted to be necessary for BCG-induced trained immunity in human monocytes (Arts et al., 2016). The implication of this for immunomodulation in cancer requires further assessment.

Subclinical doses of LPS have also been shown to prime and modulate monocyte responses in an interferon regulatory factor 5 (IRF5)-dependent manner, where TIR-domain-containing adapter-inducing interferon- $\beta$ (TRIF) and TRIF-related adaptor molecule (TRAM), but not Myd88 are involved, following TLR4 activation (Yuan et al., 2016; Geng et al., 2017). Indeed, IRF5-mediated M1 macrophage responses following LPS exposure appear to be necessary for clearing bacterial infections, concomitant with production of reactive oxygen and nitrogen intermediates (Hedl et al., 2018), both of which are necessary in controlling infections but can also promote oncogenesis. The TLR4/TRIF/TRAM pathway is also a currently investigated biological target in cancer immunotherapy (Awasthi, 2014; Guney Eskiler et al., 2019). Agonists of TLR7 have also been found to induce immune tolerance in monocytes at higher doses, while more intense TLR3 stimulation promoted an exacerbated inflammatory response (Geng et al., 2017). Both TLRs recognize RNA structures, suggesting pathogen-derived nucleic acids as a potent inducer of trained immunity, with RNAbased cancer vaccine adjuvants having been shown to induce tumor rejection and anti-viral responses without or with only minimal off-target toxicity (Seya et al., 2015; Zhu et al., 2017; Ziegler et al., 2017). In addition to TLRs, other PRRs such as melanoma-differentiation antigen 5 (MDA-5) and retinoic acidinducible gene I (RIG-I), largely involved in antiviral defense, have also been implicated in mediating tumor-cell apoptosis, DC priming and potentiation of anti-cancer cytotoxic T-cell activation (Wu et al., 2017).

A recent review by van der Heijden et al. (2018) appraised the role and significance of epigenetic modifications in innate immune cells to establish trained immunity (van der Heijden et al., 2018). Infection with $M t b$, an intracellular pathogen which prefers to reside in alveolar macrophages, has been shown to induce epigenetic changes in the host cell, i.e., modification of histones 3 and 4 acetylation patterns to promote its prolonged survival (Esterhuyse et al., 2015; Moores et al., 2017; Singh et al., 2017). Furthermore, $M t b$ also triggers the synthesis of host microRNA species to modulate immune responses to its benefit (Iannaccone et al., 2014; Huang et al., 2015; Kumar et al., 2015; von Both et al., 2018). Whether $M t b$-infected macrophages (and DCs) can modulate immune responses associated with cancer or other infections remains yet to be explored. One study has shown that infection of macrophages with $M t b$ H37Rv, a virulent, laboratory-adapted strain, upregulated PD-L1 expression which lead to increased Treg infiltration into lymph nodes and exacerbated disease in NSCLC-bearing mice (Zhou et al., 2017). It is important to be able to visualize how Mtb exposure of monocytic cells in humans may predispose them to either control or succumb to exacerbated inflammation, which may promote cancer in some individuals, and warrants thorough investigation due to the worrying global burden of TB (World Health Organization [WHO], 2018).

Another interesting point is the impact of microbial products in affecting tumor-associated macrophages (TAM), which have been reported as pro-tumoral, promoting angiogenesis, tumor-invasion, metastasis, and fine-tuning tumor-associated inflammation (Esposito et al., 2004; Qian and Pollard, 2010; Szebeni et al., 2017). The TAMs can be originated from circulating monocytes that will enter the tissue and differentiate into macrophages, bone-marrow-derived macrophages (BMDMs) or can result from an accumulation of tissueresident macrophages (TRMs) (Pathria et al., 2019). Indeed, there is a crescent number of reports correlating TAMs with higher tumor grade and shorter survival for breast cancer, renal cell carcinoma, glioblastoma, pancreatic cancer, head and neck cancer, and lymphoma (Zhang et al., 2013, 2018; Pedersen et al., 2014; Tiainen et al., 2015; Wang et al., 2015; Hu et al., 2016; Atanasov et al., 2018; Gartrell et al., 2018; Sorensen et al., 2018; Pathria et al., 2019). The relationship between TAMs and the tumor invasiveness and ability to metastasis is suggested to be related to epithelial-mesenchymal transition (EMT) (Su et al., 2014; Fu et al., 2015; Ravi et al., 2016). Indeed, Fu et al. (2015) showed that EMT hotspots in hepatocellular carcinoma were associated with TAMs infiltration ( $\mathrm{Fu}$ et al., 2015). However, TAMs and invasiveness are certainly affected by other factors, e.g., N-cadherin and Snail (Helm et al., 2014; Lin et al., 2019).

Nevertheless, the reacquisition of proinflammatory characteristics in macrophages, so called repolarization, was associated with increased survival in mice and patients with different cancer types and may be a future approach for cancer therapy (Kaneda et al., 2016b; Pathria et al., 2019). Two recent studies reported that the inhibition of phosphatidylinositol3-kinase (PI3K) by genetic depletion or pharmacological inhibition, lead to proinflammatory expression in TAMs, with a downstream effect in T-cell activation (Kaneda et al., 2016a,b). The authors also identified that a downstream effect would be to promote NF-kB phosphorylation and DNA binding activity, therefore increasing proinflammatory gene expression associated to such pathway. Another effect is the activation of Bruton's tyrosine kinase (BTK), which inhibition by ibrutinib stimulates macrophage polarization, myeloid cell infiltration reduction and increase in $\mathrm{CD} 8+\mathrm{T}$ cells infiltration in murine pancreatic ductal adenocarcinoma (PDAC) (Gunderson et al., 2016). Another molecule associated to the composition of tumor microenvironment effects is the growth arrest specific 6 (Gas6), since it interacts with TAM receptors Mer (Lew et al., 2014), with the downstream effect of PI3K, ERK, and NK-kB pathway activation. Interestingly, overexpression of Gas6 was described in a wide variety of cancers, such as melanoma, schwannoma, glioblastoma, and PDAC (Ito et al., 2002; Hutterer et al., 2008; Song et al., 2011; Demarest et al., 2013; Ammoun et al., 2014). There are other molecules that may be targeted to address the TAMs repolarization, such as receptor-interacting serine/threonine kinase 1 (RIPK1) or 
Janus kinase 2/signal transducer and activator of transcription 3 (Jak2/Stat3). The first one is increased in TAMs in human PDAC and its inhibition will repolarize TAMs and increase MHC class II, TNF- $\alpha$ and INF- $\gamma$ expression besides reducing tumor growth (Wang et al., 2018). Besides, RIPK1 inhibition will also activate CD8 $+\mathrm{T}$ cells, increase differentiation of CD $4+\mathrm{T}$ cells toward a Th1 phenotype and may have a synergic action with anti-PD-1 antibody (Wang et al., 2018). Regarding Jak2/Stat3, inhibition of Stat 3 also leads to repolarization of TAMs and increases infiltration of cytotoxic T lymphocytes (CTLs), which could also be achieved by targeting Jak2 (upstream activator) (Pathria et al., 2015). TAMs may also express a molecule named macrophage receptor with collagenous structure (MARCO), involved in the recognition of PAMPs and TLRs linking innate immune responses in the tumor - microenvironment to pathogens (Mukhopadhyay et al., 2011; Kissick et al., 2014). Indeed, TLR agonists polarize macrophages toward a proinflammatory phenotype, therefore also having a possible role for cancer therapy. The downside of such agonists is the concomitant expression of PD-L1 in macrophages, which could be blocked by the synergistic use of anti-PD-1 antibodies (Kaneda et al., 2016a,b).

\section{NK Cells}

Recent translational studies using human material have shed more light on the molecular changes in "memory-like" NK cells and ways to identify them. Hypomethylation of AT-rich interaction domain 5B (ARID5B) and co-expression of CD57, NKG2C, and reduced CD56 mark an "adaptive" subset of NK cells (Cichocki et al., 2018). Viral infection of NK cells induces the expression of natural cytotoxicity receptors (NCRs), such as NKp46, NKp44 [a HLA-DP401 ligand, which is also associated with tumor recognition (Odunsi et al., 2007; Straetemans et al., 2012; Laheurte et al., 2016; Lu et al., 2017; Niehrs et al., 2019)] and NKp30 as well as the NKG2D receptor, which binds to the non-classical HLA class I-associated molecules MICA/B on tumor cells (Cantoni et al., 2015). Particularly, human CMV infection may also drive the expansion of adaptive NK-cell populations phenotypically characterized as $\mathrm{Fc \varepsilon R} \gamma^{-}$, tyrosine kinase $\mathrm{SYK}^{-}, \mathrm{EAT}^{-}{ }^{-}$and master transcription factor PLZF ${ }^{\text {low }}$, with reduced IL-12 and IL-18 responsiveness connected to PLZF downregulation (Schlums et al., 2015). CMV-experienced Fc $\gamma$ RIII/CD16 ${ }^{+} \mathrm{NKG}^{+} \mathrm{C}^{+}$memory-like NK cells also undergo Syk DNA hypermethylation, but retain responsiveness to antibody-mediated cell expansion via CD16 binding upon exposure to CMV-infected target cells (Lee et al., 2015). As in mice, memory-like, intrahepatic NKG2C ${ }^{+} \mathrm{CD}_{49 a^{+}} \mathrm{DX}^{-} \mathrm{NK}$ cells co-expressing CD25 and IgG-like receptor, have also been described in humans (Peng et al., 2013; Marquardt et al., 2015). A recent translational study showed that "trained," intrauterine NK-cell populations with epigenetic modifications in the IFN- $\gamma$ and VEGF-A and high propensity to produce these cytokines following stimulation loci might play an important role in successful placentation (Gamliel et al., 2018). Functional studies in mice revealed that virus-induced memory-like NK cells, after contraction, go on to reside in lymphoid and non-lymphoid organs and are able to facilitate enhanced viral control following adoptive transfer (Sun et al., 2009). Thus, tissue-derived NK cells may have specific trained immunity features which are of biological relevance not only in cross-protective immunity but also tissue physiology.

The generation of memory-like NK cells has also been demonstrated by exposing them to a combination of IL-12, IL-15 and IL-18, referred to as cytokine-induced memory-like (CIML) NK cells, resulting in a population of effector cells which also exhibits superior control of K562 leukemia cells (Leong et al., 2013; Rosario et al., 2014). It is important to note that these cytokines are also produced by macrophages and DCs as a firstline immune armament during infection (Abbas et al., 2014). As such, additionally to pathogen-derived stimuli, the local cytokine milieu may also promote immunological memory in NK cells in tissue. Taking these observations into consideration, how pathogen-driven formation of immunological memory in NK cells would affect tumor immunosurveillance warrants formal testing using appropriate models and may be very significant for clinical immunotherapy.

\section{NON-IMMUNE CELLS AND TRAINED IMMUNITY}

Trained immunity in non-immune cells has been appreciated and extensively reviewed elsewhere (Hamada et al., 2019). Regulation of trained immunity in MSCs by microRNA expression and DNA methylation has been demonstrated following LPS exposure, where pro-inflammatory cytokine expression was maintained even in the absence of stimulus (Liu et al., 2015). Fibroblasts are highly specialized cells required for immune signaling during infection and tissue repair following inflammation-induced cell damage, making them a potential drug target to ameliorate chronic inflammation (Flavell et al., 2008). Their expression of TLRs and close interaction with surrounding and infiltrating immune cells places fibroblasts at an important axis linking trained immunity and immunopathology (Miteva et al., 2014). For instance, sustained activation of the Twist1-Prrx1-TNC PFL in cancer-associated fibroblasts (CAFs) perpetrates fibrotic lesions during idiopathic pulmonary fibrosis (Lederer and Martinez, 2018; Yeo et al., 2018). Tissue fibrosis, impairment of organ function and immune-suppression are also reminiscent of pulmonary TB (Dheda et al., 2005) and solid tumors (Jiang et al., 2016), hinting at similar mechanism at play. Intestinal stromal cells have been previously described to provide long-lasting pro-inflammatory immune responses against pathogens further to recruiting immune cells to the site of infection (Owens, 2015). Transformed cells, stromal cells and fibroblasts also provide a rich source of growth factors, pro-tumorigenic and immune-suppressive cytokine production that facilitates tumor progression (Todoric and Karin, 2019). Suitable disease models and well-defined clinical samples are necessary to address the role of trained non-immune cells in the cross-reactive immune responses in infectious diseases and malignant transformation. 


\section{CAN TRAINED IMMUNITY BE EXPLOITED FOR THERAPEUTIC PURPOSES?}

While trained immunity may induce unwanted, pathological inflammation and, therefore, constitutes an avenue of pharmacological intervention (Mourits et al., 2018; Mulder et al., 2019), its utility in shaping the repertoire of antigenspecific/antigen-experienced immune cells may be useful against different diseases indicates an element of "in-built adjuvanticity." In a recently reported phase 1 clinical study, BCG-vaccinated individuals given a dose of $P$. falciparum were shown to afford better control of malaria, concomitant with early activation of granzyme $\mathrm{B}^{+} \mathrm{NK}$ cells and HLA$\mathrm{DR}^{+}$monocytes (Walk et al., 2019). Non-vaccinated controls did not show similar results, suggesting that BCG-driven innate immune activation leads to cross-protection against a protozoan parasite, in keeping with a previous finding describing pro-inflammatory, adherent innate immune cells responses due to plasmodium-triggered, trained immune responses (Schrum et al., 2018). In another study, Arts et al. (2018b) reported that BCG vaccination would induce a genome-wide epigenetic reprograming of monocytes. Epigenetic changes due to $B C G$ vaccination involved $G$ protein-coupled receptors and protein kinases, and several signaling pathways involved in cytokines and chemokines production, such as the PI3K/AKT (phosphatidylinositol 3-kinase) pathway, epidermal growth factor receptor (EGFR), fibroblast growth factor (FGF), and vascular endothelial growth factor (VEGF) signaling pathways. The translation of this epigenetic reprograming was a higher pro-inflammatory cytokine production (TNF- $\alpha$, IL- $1 \beta$, and IL-6) of PBMCs from vaccinated, as compared to placebo-treated individuals, emphasizing the impact of trained immunity. Besides, these immune changes would also confer a higher protection to an unrelated infection (yellow fever virus), due to a higher production of IL-1 $\beta$, and as a trained immunity response (Arts et al., 2018b). Another interesting aspect was described by Buffen et al. (2014), reporting that BCG induced trained immunity in monocytes with an unrelated stimulus, measured by increase of IL- 6 and TNF- $\alpha$ cytokines, would not occur when autophagy was blocked. Indeed, both pharmacological inhibition of autophagy or single nucleotide polymorphisms (SNPs) in the autophagy genes (ATG2B and ATG5) reduced the trained immunity effect of BCG, due to the blocking of epigenetic reprograming of monocytes at $\mathrm{H} 3 \mathrm{~K} 4$ trimethylation (Buffen et al., 2014). Besides, the authors also describe an increase rate of recurrence and progression of non-muscular invasive bladder cancer patients after intravesical instillations of BCG in patients who exhibited SNP in the autophagy gene ATG2B. This observation supports the importance of the genetic background in non-specific effects of BCG in trained immunity and argues for genetic analyses of tissue material from patients undergoing BCG installation. Other pathogens affect as well immune cells. $C$. neoformans was shown to produce prostaglandin E2 (PGE2) to suppress T-cell activation for promoting its own growth and survival in macrophages (Evans et al., 2019). PGE2 has several important anti-inflammatory effects encompassing the TNF/IL-6/IL-17 axis and IL-8 production by inducing epigenetic modifications (Venza et al., 2012; Adamik et al., 2013; Harizi, 2015). Whether microbe-trained PGE2 production by memory-like monocytic cells may have a biologically relevant role in ameliorating chronic inflammation has to be elucidated. IFN- $\gamma$ - and LPS (TLR4)-primed macrophages, although capable of superior phagocytosis of apoptotic lymphoma cells compared to non-primed macrophages, were skewed toward an M2 (anti-inflammatory phenotype) and exhibited pro-tumor effects in vivo (Voss et al., 2017) in a preclinical (murine) model. It is, however, unknown whether TLR activation driven by factors in the tumor microenvironment (such as bacteria or fungal commensals, please see below) can promote trained immunity and, if so, whether such innate immune memory help control transformed cells and/or pathogens (see Figure 1).

\section{PERSONALIZED CANCER IMMUNOTHERAPY}

Natural killer cell-mediated immune reactivity - particularly in hematological malignancies and in combination with chimeric antigen receptor (CAR) expression - forms a central structure in cancer immunotherapy (Bjorklund et al., 2018; Tang et al., 2018). A highly favorable characteristic of NK cells pertinent to clinical use is that they are obtainable from allogeneic sources for therapy, can mediate graft-versus-leukemia (GvL) responses (Locatelli et al., 2018) and are amenable to in vitro conditioning to acquire memory-like properties (Iliopoulou et al., 2010; Liang et al., 2017). NKG2A, the NK cell/CD8 ${ }^{+} \mathrm{T}$ cell-expressed interaction partner for HLA$\mathrm{E}$ on targets cells, represents a new immune checkpoint molecule which has already shown therapeutic potential in several preclinical cancer models (Tognarelli et al., 2018; van Montfoort et al., 2018; Creelan and Antonia, 2019). NK-cell exposure to CMV induces NKG2A upregulation albeit not compromising the cells' ability to produce IFN$\gamma$ (Petersen et al., 2010). NKG2A ${ }^{+}$memory-like NK cells may, therefore, be clinically beneficial for cellular therapy of patients with HLA-E ${ }^{\text {hi }}$ malignancies (de Kruijf et al., 2010; Benevolo et al., 2011; Gooden et al., 2011; Lin et al., 2011; Bjorklund et al., 2018). CMV may also imprint on anticancer directed immune responses, which may be of clinical relevance, since CMV as well as EBV-reactive T- and B-cells infiltrate into tumor lesions (Meng et al., 2018; Lerias et al., 2019). Reprograming of tumor-associate T-cells by epigenetic targeting of CD8 + tissue resident memory (Trm) cells and tumor infiltrating T-lymphocytes (TIL) may also promote tumor control, in part by increasing "mitochondrial fitness" (Li et al., 2019).

Modulation of histone methylation using pharmacological agents has been proposed as a potential host-directed strategy to capitalize on trained innate immunity to provide immune 


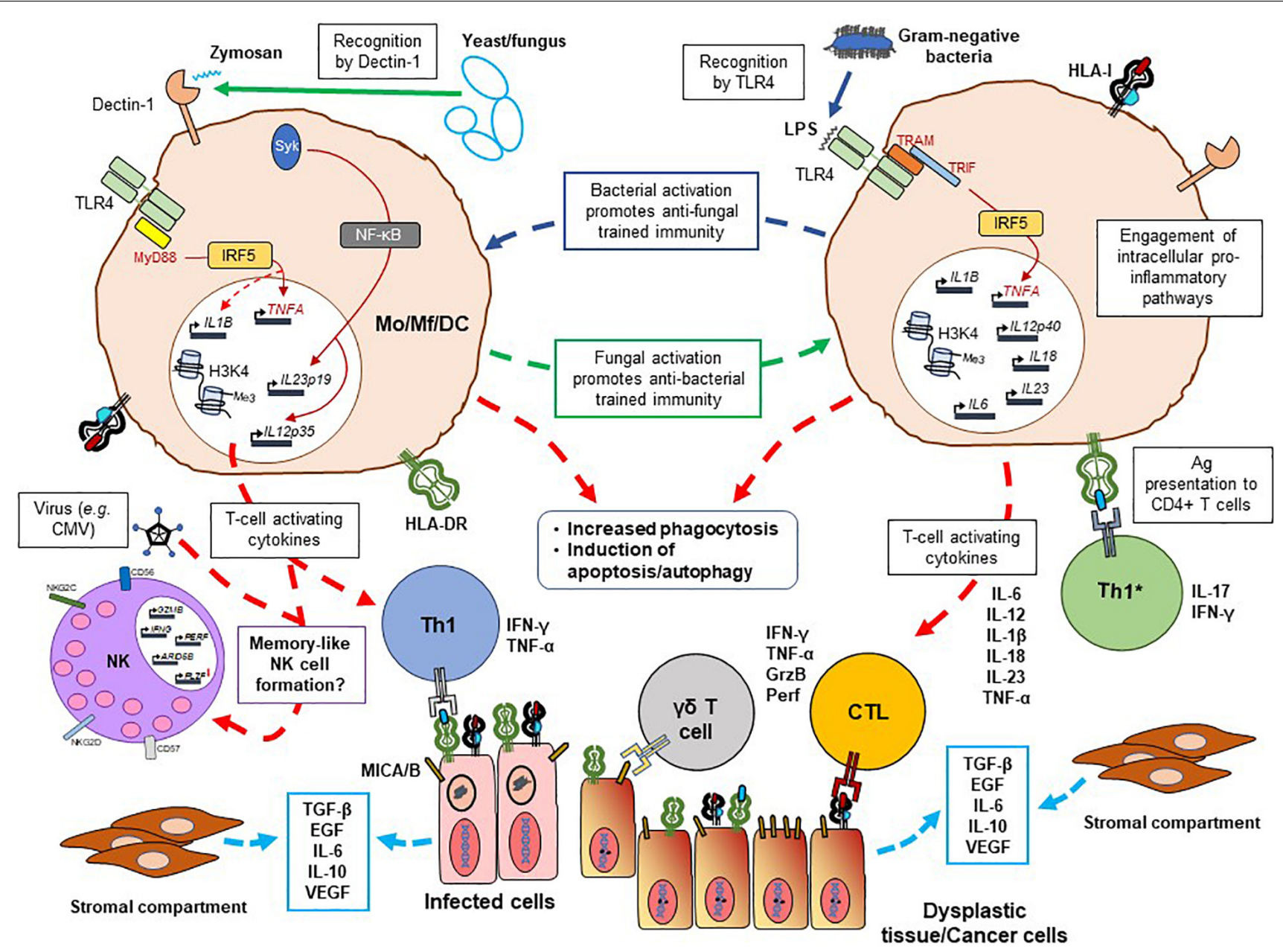

FIGURE 1 | Possible immunological processes potentiated by trained innate immunity against infections and cancer. The schematic represents some of the cardinal immune mechanisms at play in establishing trained immunity in monocytic cells, including macrophages and DCs. Bacteria-/fungi-exposed monocytes or macrophages (in response to bacterial LPS or fungal zymosan detected by pathogen recognition receptors TLR4 and Dectin-1, for example) can cross-react to either pathogen type with the production of pro-inflammatory cytokines (IL-6, TNF- $\alpha, \mathrm{IL}-1 \beta, \mathrm{IL}-18, \mathrm{LL}-12$, and IL-23) which are necessary for T-cell activation. Myd88 and/or TRIF/TRAM-mediated IRF5 activity appears to play an important role herein, along with epigenetic modification (largely involving methylation patterns) of histone 3 at position lysine 4 (H3K4). Antigen presentation via the HLA class I and class II (HLA-DR is shown in the schematic) and the inflammatory tissue environment would promote priming and expansion of T helper, cytotoxic T lymphocyte (CTL) and TCR $\gamma \delta$ T-cell populations. These T cells can eliminate infected cells and control the spread of the pathogen, and possibly react to dysplastic cells which may develop due to inflammation-driven genetic aberrations. Similarly, there may also be a direct effect of the innate immune cells - trained by exposure to pathogens - to produce an inflammation-driven response to future infections as well as cancer cells. The latter may express both classes of HLA molecules, only the TCR $\gamma \delta$ ligands MICA/B (which also binds to NKG2D on NK cells as well as $\gamma \delta \mathrm{T}$ cells), a combination of the two or HLA class II alone in the event of mutational events leading to HLA class I loss. Ongoing inflammation in tissue leads to the production of several cytokines and growth factors (e.g., TGF- $\beta$, EGF, IL-6, IL-10, and VEGF) by infected cells, dysplastic tissue and cells in the stromal compartment (activated stem cells, fibroblasts), potentially exerting a pro-tumor effect and impairing the host's anti-tumor response. The cytokine microenvironment and the possible infection with virus, such as CMV, may also promote the development of memory NK cells in tissue. Mo, monocyte; Mf, macrophage; DC, dendritic cell; HLA, human leukocyte antigen; LPS, lipopolysaccharide; IRF5, interferon regulatory factor 5; IFN- $\gamma$, interferon gamma; TNF- $\alpha$, tumor necrosis factor alpha; GrzB, granzyme B; perf, perforin; TLR, Toll-like receptor; TRIF, TIR-domain-containing adapter-inducing interferon- $\beta$; TRAM, TRIF-related adaptor molecule; Me, methyl group; TGF- $\beta$, transforming growth factor beta; EGF, epidermal growth factor; VEGF, vascular endothelial growth factor; NK, natural killer cell.

protection (Mulder et al., 2019; Rodriguez et al., 2019). Among the crucial host proteins involved in histone methylation is lysine demethylase 6B (KDM6B), also known as Jumonji Domaincontaining 3 (JMJD3). LPS activation of macrophages, a cardinal early event in sepsis, leads to downstream mobilization of several KDM6B targets, especially those associated with proinflammatory responses (De Santa et al., 2009). A similar effect is true for serum amyloid protein A (SAA)-driven inflammatory responses in macrophages (Yan et al., 2014), which is linked to the pathogenesis of rheumatoid arthritis and potentially cancer as well as metastasis (Liu, 2012; Zhou et al., 2018; Lee et al., 2019). KDM6B expression is linked to better prognosis in patients with neuroblastoma (Yang et al., 2019) and stabilization of the tumor suppressor protein 
p53 in glioblastoma stem cells (Ene et al., 2012) while its loss has been shown to promote pancreatic cancer-cell aggressiveness (Yamamoto et al., 2014). Thus, the role LPStriggered "training" of macrophages via its effect on KDM6B warrants further elucidation in the context of personalized cancer medicine.

Conversely, with respect to helminth infections, KDM6B along with IRF4 triggers the anti-inflammatory reprograming of macrophages (M2 phenotype), downstream of which manifests in Th2 cytokine release and antibody production (Satoh et al., 2010). These observations hint at the pleiotropic nature of KDM6B engagement in modulating host macrophage function as an essential therapeutic target to protect against a myriad of extrinsic (pathogen-associated) and intrinsic (host-associated) insults. Interestingly, amino acids 11101120 of KDM6B contain a strong 8 amino-acid match with selected residues between positions 251-265 in the influenza A virus (H1N1) hemagglutinin (HA) protein (derived from the California/New York strains of the 2009 pandemic flu), which provides a small hint about molecular mimicry and the possibility of TCR binding. Further studies are necessary to understand how preprograming of KDM6B activity affects disease outcome in infectious diseases.

The microbiome has an important role in promoting trained immunity due to effect in development of the immune system, host control of chronic infections (e.g., TB), and clinical responses to immune checkpoint blockade in cancer for developing next-generation personalized cancer immunotherapies (Nash et al., 2017; Cassone, 2018; Gupta et al., 2018; Fessler et al., 2019). Indeed, gut microbial/non-microbial ligands are essential for the adaptative immunity during secondary infection/pathogenic exposures, being involved in the production of immunomodulatory metabolites, such as short-chain fatty acids or secondary bile acids, regulating innate immune cells metabolism and functions (Kitahara et al., 2001; Tremaroli and Backhed, 2012; Levy et al., 2016; Rooks and Garrett, 2016; Jia et al., 2018). Importantly, commensals in the gut are involved in the production of immunomodulatory metabolites that comprise short-chain fatty acids (SCFAs) such as butyrate, acetate, and propionate (50-52). Further, commensals such as Bacteroides, Lactobacillus, and Bifidobacteria species synthesize secondary bile acids that are derived from the metabolism of primary bile acids (53-55). Binding of these bioactive molecules to the receptors on the innate cells regulate their metabolism and functions (Negi et al., 2019). Cancer associated microbiomes have recently been linked to clinical outcomes in pancreatic cancer: The mycobiome (fungal components of the microbiome) has been shown to accelerate pancreatic cancer, via a carbohydrate moiety on Malassezia that activates the complement pathway (Aykut et al., 2019). In contrast, the tumor microbiome characterized by Saccharolpolyspora, Pseudoxanthomonas, Bacillius clausii and Streptomyces species has been associated with long-term survival for patients with pancreatic cancer
(Riquelme et al., 2019). Future studies will show the impact of these bacterial/fungal species and their metabolites on immune cell programing.

Cancer antigens are released into the external environment usually by dying cells or packaged in exosomes (Wolfers et al., 2001). This may (i) facilitate training of immune cells and help them respond to a future infection or other cancer indications or (ii) activate immune cells subsets which are pre-wired - by a previous infection or exposure to autoantigens - to exhibit enhanced phagocytic functions, cytokine production capacity and unleash strong anti-tumor T-cell responses (Netea et al., 2017). Indeed, the durable changes after training of innate myeloid cells, involve the increase of expression and release of cytokines associated to a long-term regulation of gene transcription through epigenetic mechanisms (Foster et al., 2007; Quintin et al., 2012; Netea et al., 2017). More specific effects of trained immune cells is, for example, the switch from oxidative phosphorylation to glycolysis in trained monocytes (Cheng et al., 2014). Besides, trained monocytes also show the accumulation of fumarate in the Krebs cycle, inhibiting the KDM5 family of $\mathrm{H} 3 \mathrm{~K} 4$ demethylases, therefore ensuring the maintenance of the H3K4me3 open chromatin mark (Sun et al., 2015).

Dendritic cells -based vaccination constitutes a major area of targeted personalized immunotherapy, with naturally occurring circulating DCs with certain pre-programed characteristics being considered of value for therapeutic applications (Bol et al., 2019). Herein, trained immunity in DCs - such as that shown in response to anti-C. neoformans vaccination (Hole et al., 2019) - warrants investigation in the context of tailored anti-cancer immune responses. The DC vaccines involve the ability of these cells to act as an antitumoral effector in both CTLs and NK cells, in order to eradicate malignant cells (Kirkwood et al., 2012). There are several types of DC-vaccines, being the most frequently used the reinfusion of ex vivo derived DC pulsed with tumor-associated antigens (TAAs) or tumor cell lysates and stimulated with TNF- $\alpha$, IL-1 $\beta$, IL-6, and prostaglandin E2 (PGE2) (Lee et al., 2002; Koski et al., 2008; Anguille et al., 2014). The DC-based immunotherapy efficiency may be enhanced using immune checkpoint inhibitors, such as anti PD-1 or anti-CTLA-4 antibodies (Mastelic-Gavillet et al., 2019). Carreno and colleges described the vaccination of three stage III resected melanoma patients who received mature autologous DCs pulsed with peptides derived from mutated antigens, with a previous treatment with CTLA-4 blockade. Interestingly, besides the identification of peptidespecific $\mathrm{T}$ cell responses, after vaccination blood samples showed a more diverse TCR repertoire (Carreno et al., 2015). DC vaccines can also be considered to be combined with chemotherapy, since it is reported that chemotherapy may deplete specific cell types, such as Tregs and myeloid derived suppressor cells (MDSCs) and modulate the immune system to a more pro-inflammatory state (Kershaw et al., 2013; Bracci et al., 2014). 


\section{CONCLUSION}

With increasing evidence emerging from basic and translational studies, trained immunity warrants further dissection for its capacity to offer powerful and durable anti-cancer immune responses - and potential reprograming of "non-productive" to "productive" (i.e., anti-cancer or pathogen-directed) immune responses. A large repertoire of innate immune and nonimmunes cells enriches the repertoire of responders to insults of various origins and nature, and their interplay in shaping immunity. Combining biomarker information from various clinical studies and drug trials will increase the possibilities for designing treatment strategies. Trained immunity-based approaches will inevitably enhance T-cell responses in conferring

\section{REFERENCES}

Abbas, A., Lichtman, A. H., and Pilai, S. (2014). Basic Immunology: Functions and Disorders of the Immune System. Philadelphia: W.B. Saunders Company.

Adamik, J., Henkel, M., Ray, A., Auron, P. E., Duerr, R., and Barrie, A. (2013). The IL17A and IL17F loci have divergent histone modifications and are differentially regulated by prostaglandin E2 in Th17 cells. Cytokine 64, 404-412. doi: 10.1016/ j.cyto.2013.05.010

Ammoun, S., Provenzano, L., Zhou, L., Barczyk, M., Evans, K., Hilton, D. A., et al. (2014). Axl/Gas6/NFkappaB signalling in schwannoma pathological proliferation, adhesion and survival. Oncogene 33, 336-346. doi: 10.1038/onc. 2012.587

Anguille, S., Smits, E. L., Lion, E., van Tendeloo, V. F., and Berneman, Z. N. (2014). Clinical use of dendritic cells for cancer therapy. Lancet Oncol. 15, e257-e267. doi: 10.1016/S1470-2045(13)70585-0

Arts, R. J. W., Carvalho, A., La Rocca, C., Palma, C., Rodrigues, F., Silvestre, R., et al. (2016). Immunometabolic pathways in BCG-induced trained immunity. Cell Rep. 17, 2562-2571. doi: 10.1016/j.celrep.2016.11.011

Arts, R. J. W., Joosten, L. A. B., and Netea, M. G. (2018a). The potential role of trained immunity in autoimmune and autoinflammatory disorders. Front. Immunol. 9:298. doi: 10.3389/fimmu.2018.00298

Arts, R. J. W., Moorlag, S., Novakovic, B., Li, Y., Wang, S. Y., Oosting, M., et al. (2018b). BCG vaccination protects against experimental viral infection in humans through the induction of cytokines associated with trained immunity. Cell Host Microbe 23:89-100.e5. doi: 10.1016/j.chom.2017.12.010

Atanasov, G., Potner, C., Aust, G., Schierle, K., Dietel, C., Benzing, C., et al. (2018). TIE2-expressing monocytes and M2-polarized macrophages impact survival and correlate with angiogenesis in adenocarcinoma of the pancreas. Oncotarget 9, 29715-29726. doi: 10.18632/oncotarget.25690

Awasthi, S. (2014). Toll-like receptor-4 modulation for cancer immunotherapy. Front. Immunol. 5:328-328. doi: 10.3389/fimmu.2014.00328

Aykut, B., Pushalkar, S., Chen, R., Li, Q., Abengozar, R., Kim, J. I., et al. (2019). The fungal mycobiome promotes pancreatic oncogenesis via activation of MBL. Nature 574, 264-267. doi: 10.1038/s41586-019-1608-2

Balkwill, F. (2009). Tumour necrosis factor and cancer. Nat. Rev. Cancer 9:361. doi: $10.1038 / \mathrm{nrc} 2628$

Beamer, G., Major, S., Das, B., and Campos-Neto, A. (2014). Bone marrow mesenchymal stem cells provide an antibiotic-protective niche for persistent viable Mycobacterium tuberculosis that survive antibiotic treatment. Am. J. Pathol. 184, 3170-3175. doi: 10.1016/j.ajpath.2014.08.024

Benevolo, M., Mottolese, M., Tremante, E., Rollo, F., Diodoro, M. G., Ercolani, C., et al. (2011). High expression of HLA-E in colorectal carcinoma is associated with a favorable prognosis. J. Transl. Med. 9:184. doi: 10.1186/1479-58769-184

Bent, R., Moll, L., Grabbe, S., and Bros, M. (2018). Interleukin-1 Beta-A friend or foe in malignancies? Int. J. Mol. Sci. 19:2155. doi: 10.3390/ijms19082155

Bisiaux, A., Thiounn, N., Timsit, M. O., Eladaoui, A., Chang, H. H., Mapes, J., et al. (2009). Molecular analyte profiling of the early events and tissue conditioning following intravesical bacillus calmette-guerin therapy in patients host protection and facilitating long-term adaptive memory responses against pathogens or transformed cells.

\section{AUTHOR CONTRIBUTIONS}

MR, JL, AZ, and MM wrote the first draft and conceptualized the review. All authors were involved in further development, writing and proofreading of the review.

\section{FUNDING}

This work was supported by the Champalimaud Foundation.

with superficial bladder cancer. J. Urol. 181, 1571-1580. doi: 10.1016/j.juro. 2008.11.124

Biswas, S. K. (2015). Metabolic reprogramming of immune cells in cancer progression. Immunity 43, 435-449. doi: 10.1016/j.immuni.2015.09.001

Bjorklund, A. T., Carlsten, M., Sohlberg, E., Liu, L. L., Clancy, T., Karimi, M., et al. (2018). Complete remission with reduction of high-risk clones following haploidentical NK-cell therapy against MDS and AML. Clin. Cancer Res. 24, 1834-1844. doi: 10.1158/1078-0432.CCR-17-3196

Bol, K. F., Schreibelt, G., Rabold, K., Wculek, S. K., Schwarze, J. K., Dzionek, A., et al. (2019). The clinical application of cancer immunotherapy based on naturally circulating dendritic cells. J. ImmunoTher. Cancer 7:109. doi: 10.1186/ s40425-019-0580-6

Bracci, L., Schiavoni, G., Sistigu, A., and Belardelli, F. (2014). Immune-based mechanisms of cytotoxic chemotherapy: implications for the design of novel and rationale-based combined treatments against cancer. Cell Death. Differ. 21, 15-25. doi: 10.1038/cdd.2013.67

Buffen, K., Oosting, M., Quintin, J., Ng, A., Kleinnijenhuis, J., Kumar, V., et al. (2014). Autophagy controls BCG-induced trained immunity and the response to intravesical BCG therapy for bladder cancer. PLoS Pathog. 10:e1004485. doi: 10.1371/journal.ppat.1004485

Cantoni, C., Grauwet, K., Pietra, G., Parodi, M., Mingari, M. C., Maria, A. D., et al. (2015). Role of NK cells in immunotherapy and virotherapy of solid tumors. Immunotherapy 7, 861-882. doi: 10.2217/imt.15.53

Carreno, B. M., Magrini, V., Becker-Hapak, M., Kaabinejadian, S., Hundal, J., Petti, A. A., et al. (2015). Cancer immunotherapy. a dendritic cell vaccine increases the breadth and diversity of melanoma neoantigen-specific T cells. Science 348 , 803-808. doi: 10.1126/science.aaa3828

Cassone, A. (2018). The case for an expanded concept of trained immunity. mBio 9:e570-18. doi: 10.1128/mBio.00570-18

Cheng, S. C., Quintin, J., Cramer, R. A., Shepardson, K. M., Saeed, S., Kumar, V., et al. (2014). mTOR- and HIF-1alpha-mediated aerobic glycolysis as metabolic basis for trained immunity. Science 345:1250684. doi: 10.1126/science.1250684

Cichocki, F., Wu, C. Y., Zhang, B., Felices, M., Tesi, B., Tuininga, K., et al. (2018). ARID5B regulates metabolic programming in human adaptive NK cells. J. Exp. Med. 215, 2379-2395. doi: 10.1084/jem.20172168

Creelan, B. C., and Antonia, S. J. (2019). The NKG2A immune checkpoint-a new direction in cancer immunotherapy. Nat. Rev. Clin. Oncol. 16, 277-278. doi: 10.1038/s41571-019-0182-8

Crowley, T., Buckley, C. D., and Clark, A. R. (2018). Stroma: the forgotten cells of innate immune memory. Clin. Exp. Immunol. 193, 24-36. doi: 10.1111/cei. 13149

Das, B., Kashino, S. S., Pulu, I., Kalita, D., Swami, V., Yeger, H., et al. (2013). CD271(+) bone marrow mesenchymal stem cells may provide a niche for dormant Mycobacterium tuberculosis. Sci. Transl. Med. 5:170ra13. doi: 10.1126/ scitranslmed.3004912

de Kruijf, E. M., Sajet, A., van Nes, J. G., Natanov, R., Putter, H., Smit, V. T., et al. (2010). HLA-E and HLA-G expression in classical HLA class I-negative tumors is of prognostic value for clinical outcome of early breast cancer patients. J. Immunol. 185, 7452-7459. doi: 10.4049/jimmunol.1002629 
De Santa, F., Narang, V., Yap, Z. H., Tusi, B. K., Burgold, T., Austenaa, L., et al. (2009). Jmjd3 contributes to the control of gene expression in LPS-activated macrophages. EMBO J. 28, 3341-3352. doi: 10.1038/emboj.2009.271

Demarest, S. J., Gardner, J., Vendel, M. C., Ailor, E., Szak, S., Huang, F., et al. (2013). Evaluation of Tyro3 expression, Gas6-mediated Akt phosphorylation, and the impact of anti-Tyro3 antibodies in melanoma cell lines. Biochemistry 52, 3102-3118. doi: 10.1021/bi301588c

Dheda, K., Booth, H., Huggett, J. F., Johnson, M. A., Zumla, A., and Rook, G. A. (2005). Lung remodeling in pulmonary tuberculosis. J. Infect. Dis. 192, 1201-1209. doi: 10.1086/444545

Ene, C. I., Edwards, L., Riddick, G., Baysan, M., Woolard, K., Kotliarova, S., et al. (2012). Histone demethylase Jumonji D3 (JMJD3) as a tumor suppressor by regulating p53 protein nuclear stabilization. PLoS One 7:e51407. doi: 10.1371/ journal.pone.0051407

Esposito, I., Menicagli, M., Funel, N., Bergmann, F., Boggi, U., Mosca, F., et al. (2004). Inflammatory cells contribute to the generation of an angiogenic phenotype in pancreatic ductal adenocarcinoma. J. Clin. Pathol. 57, 630-636. doi: $10.1136 /$ jcp.2003.014498

Esterhuyse, M. M., Weiner, J. I. I. I., Caron, E., Loxton, A. G., Iannaccone, M., Wagman, C., et al. (2015). Epigenetics and proteomics join transcriptomics in the quest for tuberculosis biomarkers. mBio 6:e1187-15. doi: 10.1128/mBio. 01187- 15

Evans, R. J., Pline, K., Loynes, C. A., Needs, S., Aldrovandi, M., Tiefenbach, J., et al. (2019). 15-keto-prostaglandin E2 activates host peroxisome proliferator-activated receptor gamma (PPAR- $\gamma$ ) to promote Cryptococcus neoformans growth during infection. PLoS Pathog. 15:e1007597. doi: 10.1371/ journal.ppat.1007597

Fessler, J., Matson, V., and Gajewski, T. F. (2019). Exploring the emerging role of the microbiome in cancer immunotherapy. J. ImmunoTher. Cancer 7:108. doi: 10.1186/s40425-019-0574-4

Flavell, S. J., Hou, T. Z., Lax, S., Filer, A. D., Salmon, M., and Buckley, C. D. (2008). Fibroblasts as novel therapeutic targets in chronic inflammation. Br. J. Pharmacol. 153, S241-S246.

Foster, S. L., Hargreaves, D. C., and Medzhitov, R. (2007). Gene-specific control of inflammation by TLR-induced chromatin modifications. Nature 447, 972-978. doi: $10.1038 /$ nature05836

Francois, B., Jeannet, R., Daix, T., Walton, A. H., Shotwell, M. S., Unsinger, J., et al. (2018). Interleukin-7 restores lymphocytes in septic shock: the IRIS-7 randomized clinical trial. JCI Insight 3:98960. doi: 10.1172/jci.insight.98960

Fu, X. T., Dai, Z., Song, K., Zhang, Z. J., Zhou, Z. J., Zhou, S. L., et al. (2015). Macrophage-secreted IL-8 induces epithelial-mesenchymal transition in hepatocellular carcinoma cells by activating the JAK2/STAT3/Snail pathway. Int. J. Oncol. 46, 587-596. doi: 10.3892/ijo.2014.2761

Gamliel, M., Goldman-Wohl, D., Isaacson, B., Gur, C., Stein, N., Yamin, R., et al. (2018). Trained memory of human uterine NK cells enhances their function in subsequent pregnancies. Immunity 48:951-962.e5. doi: 10.1016/j.immuni.2018. 03.030

Gartrell, R. D., Marks, D. K., Hart, T. D., Li, G., Davari, D. R., Wu, A., et al. (2018). Quantitative analysis of immune infiltrates in primary melanoma. Cancer Immunol. Res. 6, 481-493. doi: 10.1158/2326-6066.CIR-17-0360

Geng, S., Yuan, R., and Li, L. (2017). Dynamic programming and memory of monocytes by varying signal strengths of innate stimulants. J. Immunol. 198(1 Suppl):221.14.

Gooden, M., Lampen, M., Jordanova, E. S., Leffers, N., Trimbos, J. B., van der Burg, S. H., et al. (2011). HLA-E expression by gynecological cancers restrains tumorinfiltrating CD8 ${ }^{+} \mathrm{T}$ lymphocytes. Proc. Natl. Acad. Sci. U.S.A. 108:10656-61. doi: 10.1073/pnas.1100354108

Gourbal, B., Pinaud, S., Beckers, G. J. M., Van Der Meer, J. W. M., Conrath, U., and Netea, M. G. (2018). Innate immune memory: an evolutionary perspective. Immunol. Rev. 283, 21-40. doi: 10.1111/imr.12647

Groh, L., Keating, S. T., Joosten, L. A. B., Netea, M. G., and Riksen, N. P. (2017). Monocyte and macrophage immunometabolism in atherosclerosis. Semi. Immunopathol. 40, 203-214. doi: 10.1007/s00281-017-0656-7

Gross, S., Erdmann, M., Haendle, I., Voland, S., Berger, T., Schultz, E., et al. (2017). Twelve-year survival and immune correlates in dendritic cellvaccinated melanoma patients. JCI Insight 2:e91438. doi: 10.1172/jci.insight. 91438

Gunderson, A. J., Kaneda, M. M., Tsujikawa, T., Nguyen, A. V., Affara, N. I., Ruffell, B., et al. (2016). Bruton tyrosine kinase-dependent immune cell cross-talk drives pancreas cancer. Cancer Discov. 6, 270-285. doi: 10.1158/2159-8290.CD-150827

Guney Eskiler, G., Deveci Ozkan, A., Kaleli, S., and Bilir, C. (2019). Inhibition of TLR4/TRIF/IRF3 signaling pathway by curcumin in breast cancer cells. J. Pharm. Pharm. Sci. 22, 281-291. doi: 10.18433/jpps30493

Gupta, N., Kumar, R., and Agrawal, B. (2018). New players in immunity to tuberculosis: the host microbiome, lung epithelium, and innate immune cells. Front. Immunol. 9:709. doi: 10.3389/fimmu.2018.00709

Hamada, A., Torre, C., Drancourt, M., and Ghigo, E. (2019). Trained immunity carried by non-immune cells. Front. Microbiol. 9:3225-3225. doi: 10.3389/ fmicb.2018.03225

Harizi, H. (2015). Epigenetic regulations of inflammatory cyclooxygenase-derived prostanoids: molecular basis and pathophysiological consequences. Media. Inflamm. 2015:9. doi: 10.1155/2015/841097

Hedl, M., Yan, J., Witt, H., and Abraham, C. (2018). IRF5 is required for bacterial clearance in human M1-polarized macrophages, and IRF5 immune-mediated disease risk variants modulate this outcome. J. Immunol. 202, 920-930. doi: 10.4049/jimmunol.1800226

Helm, O., Held-Feindt, J., Grage-Griebenow, E., Reiling, N., Ungefroren, H., Vogel, I., et al. (2014). Tumor-associated macrophages exhibit pro- and antiinflammatory properties by which they impact on pancreatic tumorigenesis. Int. J. Cancer 135, 843-861. doi: 10.1002/ijc.28736

Hole, C. R., Wager, C. M. L., Castro-Lopez, N., Campuzano, A., Cai, H., Wozniak, K. L., et al. (2019). Induction of memory-like dendritic cell responses in vivo. Nat. Commun. 10:2955. doi: 10.1038/s41467-019-10486-5

Hu, Y., He, M. Y., Zhu, L. F., Yang, C. C., Zhou, M. L., Wang, Q., et al. (2016). Tumor-associated macrophages correlate with the clinicopathological features and poor outcomes via inducing epithelial to mesenchymal transition in oral squamous cell carcinoma. J. Exp. Clin. Cancer Res. 35, 12. doi: 10.1186/s13046015-0281-z

Huang, J., Jiao, J., Xu, W., Zhao, H., Zhang, C., Shi, Y., et al. (2015). MiR-155 is upregulated in patients with active tuberculosis and inhibits apoptosis of monocytes by targeting FOXO3. Mol. Med. Rep. 12, 7102-7108. doi: 10.3892/ mmr.2015.4250

Hutterer, M., Knyazev, P., Abate, A., Reschke, M., Maier, H., Stefanova, N., et al. (2008). Axl and growth arrest-specific gene 6 are frequently overexpressed in human gliomas and predict poor prognosis in patients with glioblastoma multiforme. Clin. Cancer Res. 14, 130-138. doi: 10.1158/1078-0432.CCR-070862

Iannaccone, M., Dorhoi, A., and Kaufmann, S. H. (2014). Host-directed therapy of tuberculosis: what is in it for microRNA? Expert. Opin. Ther. Targets 18, 491-494. doi: 10.1517/14728222.2014.897696

Ikeda, N., Toida, I., Iwasaki, A., Kawai, K., and Akaza, H. (2002). Surface antigen expression on bladder tumor cells induced by bacillus Calmette-Guerin (BCG): a role of BCG internalization into tumor cells. Int. J. Urol. 9, 29-35. doi: 10.1046/j.1442-2042.2002.00415.x

Ilangumaran, S., Finan, D., La Rose, J., Raine, J., Silverstein, A., De Sepulveda, P., et al. (2002). A positive regulatory role for suppressor of cytokine signaling 1 in IFN-gamma-induced MHC class II expression in fibroblasts. J. Immunol. 169, 5010-5020. doi: 10.4049/jimmunol.169.9.5010

Iliopoulou, E. G., Kountourakis, P., Karamouzis, M. V., Doufexis, D., Ardavanis, A., Baxevanis, C. N., et al. (2010). A phase I trial of adoptive transfer of allogeneic natural killer cells in patients with advanced non-small cell lung cancer. Cancer Immunol. Immunother. 59, 1781-1789. doi: 10.1007/s00262010-0904-3

Ito, M., Nakashima, M., Nakayama, T., Ohtsuru, A., Nagayama, Y., Takamura, N., et al. (2002). Expression of receptor-type tyrosine kinase, Axl, and its ligand, Gas6, in pediatric thyroid carcinomas around chernobyl. Thyroid 12, 971-975. doi: 10.1089/105072502320908303

Jensen, K. J., Larsen, N., Biering-Sorensen, S., Andersen, A., Eriksen, H. B., Monteiro, I., et al. (2015). Heterologous immunological effects of early BCG vaccination in low-birth-weight infants in Guinea-Bissau: a randomizedcontrolled trial. J. Infect. Dis. 211, 956-967. doi: 10.1093/infdis/jiu508

Jia, W., Xie, G., and Jia, W. (2018). Bile acid-microbiota crosstalk in gastrointestinal inflammation and carcinogenesis. Nat. Rev. Gastroenterol. Hepatol. 15, 111-128. doi: $10.1038 /$ nrgastro.2017.119

Jiang, B. (2017). Aerobic glycolysis and high level of lactate in cancer metabolism and microenvironment. Genes Dis. 4, 25-27. doi: 10.1016/j.gendis.2017. 02.003 
Jiang, H., Hegde, S., Knolhoff, B. L., Zhu, Y., Herndon, J. M., Meyer, M. A., et al. (2016). Targeting focal adhesion kinase renders pancreatic cancers responsive to checkpoint immunotherapy. Nat. Med. 22, 851-860. doi: 10.1038/nm.4123

Kaneda, M. M., Cappello, P., Nguyen, A. V., Ralainirina, N., Hardamon, C. R., Foubert, P., et al. (2016a). Macrophage PI3Kgamma drives pancreatic ductal adenocarcinoma progression. Cancer Discov. 6, 870-885. doi: 10.1158/21598290.cd-15-1346

Kaneda, M. M., Messer, K. S., Ralainirina, N., Li, H., Leem, C. J., Gorjestani, S., et al. (2016b). PI3Kgamma is a molecular switch that controls immune suppression. Nature 539, 437-442. doi: 10.1038/nature19834

Kanjanapradit, K., Kosjerina, Z., Tanomkiat, W., Keeratichananont, W., and Panthuwong, S. (2017). Pulmonary cryptococcosis presenting with lung mass: report of 7 cases and review of literature. Clin. Med. Insights Pathol. 10:1179555717722962. doi: 10.1177/1179555717722962

Kaufmann, E., Sanz, J., Dunn, J. L., Khan, N., Mendonca, L. E., Pacis, A., et al. (2018). BCG educates hematopoietic stem cells to generate protective innate immunity against tuberculosis. Cell 172:176-190.e19.

Kershaw, M. H., Devaud, C., John, L. B., Westwood, J. A., and Darcy, P. K. (2013). Enhancing immunotherapy using chemotherapy and radiation to modify the tumor microenvironment. Oncoimmunology 2:e25962. doi: 10.4161/onci. 25962

Khan, A., Mann, L., Papanna, R., Lyu, A., Singh, C. R., Olson, S., et al. (2017). Mesenchymal stem cells internalize Mycobacterium tuberculosis through scavenger receptors and restrict bacterial growth through autophagy. Sci. Rep. 7:15010. doi: 10.1038/s41598-017-15290-Z

Kirkwood, J. M., Butterfield, L. H., Tarhini, A. A., Zarour, H., Kalinski, P., and Ferrone, S. (2012). Immunotherapy of cancer in 2012. CA Cancer J. Clin. 62, 309-335. doi: 10.3322/caac.20132

Kissick, H. T., Dunn, L. K., Ghosh, S., Nechama, M., Kobzik, L., and Arredouani, M. S. (2014). The scavenger receptor MARCO modulates TLR-induced responses in dendritic cells. PLoS One 9:e104148. doi: 10.1371/journal.pone. 0104148

Kitahara, M., Takamine, F., Imamura, T., and Benno, Y. (2001). Clostridium hiranonis sp. nov., a human intestinal bacterium with bile acid 7alphadehydroxylating activity. Int. J. Syst. Evol. Microbiol. 51, 39-44. doi: 10.1099/ 00207713-51-1-39

Koski, G. K., Cohen, P. A., Roses, R. E., Xu, S., and Czerniecki, B. J. (2008). Reengineering dendritic cell-based anti-cancer vaccines. Immunol. Rev. 222, 256-276. doi: 10.1111/j.1600-065X.2008.00617.x

Kumar, M., Sahu, S. K., Kumar, R., Subuddhi, A., Maji, R. K., Jana, K., et al. (2015). MicroRNA let-7 modulates the immune response to Mycobacterium tuberculosis infection via Control of A20, an Inhibitor of the NF-\&\#x3ba;B Pathway. Cell Host Microbe 17, 345-356. doi: 10.1016/j.chom.2015.01.007

Laheurte, C., Galaine, J., Beziaud, L., Dosset, M., Kerzerho, J., Jacquemard, C., et al. (2016). Immunoprevalence and magnitude of HLA-DP4 versus HLA-DR-restricted spontaneous CD4(+) Th1 responses against telomerase in cancer patients. Oncoimmunology 5:e1137416. doi: 10.1080/2162402X.2015.11 37416

Lederer, D. J., and Martinez, F. J. (2018). Idiopathic pulmonary fibrosis. N. Engl. J. Med. 378, 1811-1823.

Lee, A. W., Truong, T., Bickham, K., Fonteneau, J.-F., Larsson, M., Da Silva, I., et al. (2002). A clinical grade cocktail of cytokines and PGE2 results in uniform maturation of human monocyte-derived dendritic cells: implications for immunotherapy. Vaccine 20, A8-A22.

Lee, J., Zhang, T., Hwang, I., Kim, A., Nitschke, L., Kim, M., et al. (2015). Epigenetic modification and antibody-dependent expansion of memory-like NK cells in human cytomegalovirus-infected individuals. Immunity 42, 431-442. doi: 10. 1016/j.immuni.2015.02.013

Lee, J. W., Stone, M. L., Porrett, P. M., Thomas, S. K., Komar, C. A., Li, J. H., et al. (2019). Hepatocytes direct the formation of a pro-metastatic niche in the liver. Nature 567, 249-252. doi: 10.1038/s41586-019-1004-y

Leong, J. W., Schneider, S. E., Sullivan, R. P., Cooper, M., and Fehniger, T. A. (2013). Human cytokine-induced memory-like (CIML) NK cells exhibit potent antileukemia cytotoxicity and maintain memory-like functionality after adoptive transfer into immunodeficient NOD-SCID-Gc-/- (NSG) Mice. Blood 122:4501. doi: 10.1182/blood.v122.21.4501.4501

Lerias, J. R., Paraschoudi, G., Silva, I., Martins, J., de Sousa, E., Condeco, C., et al. (2019). Clinically relevant immune responses against cytomegalovirus: implications for precision medicine. Int. J. Mol. Sci. 20:E1986. doi: 10.3390/ ijms20081986

Levy, M., Thaiss, C. A., and Elinav, E. (2016). Metabolites: messengers between the microbiota and the immune system. Genes Dev. 30, 1589-1597. doi: 10.1101/ gad.284091.116

Lew, E. D., Oh, J., Burrola, P. G., Lax, I., Zagórska, A., Través, P. G., et al. (2014). Differential TAM receptor-ligand-phospholipid interactions delimit differential TAM bioactivities. eLife 3:e03385.

Li, C., Zhu, B., Son, Y. M., Wang, Z., Jiang, L., Xiang, M., et al. (2019). The transcription factor Bhlhe40 programs mitochondrial regulation of resident CD8(+) T Cell fitness and functionality. Immunity 51:e7. doi: 10.1016/j. immuni.2019.08.013

Liang, S., Xu, K., Niu, L., Wang, X., Liang, Y., Zhang, M., et al. (2017). Comparison of autogeneic and allogeneic natural killer cells immunotherapy on the clinical outcome of recurrent breast cancer. Oncotargets Ther. 10, 4273-4281. doi: 10. 2147/OTT.S139986

Lin, A., Zhang, X., Ruan, Y. Y., Wang, Q., Zhou, W. J., and Yan, W. H. (2011). HLA$\mathrm{F}$ expression is a prognostic factor in patients with non-small-cell lung cancer. Lung Cancer 74, 504-509. doi: 10.1016/j.lungcan.2011.04.006

Lin, Y., Xu, J., and Lan, H. (2019). Tumor-associated macrophages in tumor metastasis: biological roles and clinical therapeutic applications. J. Hematol. Oncol. 12:76. doi: 10.1186/s13045-019-0760-3

Liu, C. (2012). Serum amyloid a protein in clinical cancer diagnosis. Pathol. Oncol. Res. 18, 117-121. doi: 10.1007/s12253-011-9459-7

Liu, G. Y., Liu, Y., Lu, Y., Qin, Y. R., Di, G. H., Lei, Y. H., et al. (2015). Shortterm memory of danger signals or environmental stimuli in mesenchymal stem cells: implications for therapeutic potential. Cell. Mol. Immunol. 13:369. doi: $10.1038 / \mathrm{cmi} .2015 .11$

Locatelli, F., Pende, D., Falco, M., Della Chiesa, M., Moretta, A., and Moretta, L. (2018). NK Cells mediate a crucial graft-versus-leukemia effect in haploidentical-HSCT to cure high-risk acute leukemia. Trends Immunol. 39, 577-590. doi: 10.1016/j.it.2018.04.009

Lu, Y. C., Parker, L. L., Lu, T., Zheng, Z., Toomey, M. A., White, D. E., et al. (2017). Treatment of patients with metastatic cancer using a major histocompatibility complex class II-restricted T-Cell receptor targeting the cancer germline antigen MAGE-A3. J. Clin. Oncol. 35, 3322-3329. doi: 10.1200/JCO.2017.74.5463

MacGillivray, D. M., and Kollmann, T. R. (2014). The role of environmental factors in modulating immune responses in early life. Front. Immunol. 5:434. doi: 10.3389/fimmu.2014.00434

Madej, M. P., Töpfer, E., Boraschi, D., and Italiani, P. (2017). Different regulation of interleukin-1 production and activity in monocytes and macrophages: innate memory as an endogenous mechanism of IL-1 inhibition. Front. Pharmacol. 8:335. doi: 10.3389/fphar.2017.00335

Maeurer, M. J., Martin, D., Walter, W., Liu, K., Zitvogel, L., Halusczcak, K., et al. (1996). Human intestinal Vdelta1+ lymphocytes recognize tumor cells of epithelial origin. J. Exp. Med. 183, 1681-1696. doi: 10.1084/jem.183.4.1681

Mantovani, A., Barajon, I., and Garlanda, C. (2018). IL-1 and IL-1 regulatory pathways in cancer progression and therapy. Immunol. Rev. 281, 57-61. doi: 10.1111/imr.12614

Marquardt, N., Beziat, V., Nystrom, S., Hengst, J., Ivarsson, M. A., Kekalainen, E., et al. (2015). Cutting edge: identification and characterization of human intrahepatic CD49a+ NK cells. J. Immunol. 194, 2467-2471. doi: 10.4049/ jimmunol.1402756

Mastelic-Gavillet, B., Balint, K., Boudousquie, C., Gannon, P. O., and Kandalaft, L. E. (2019). Personalized dendritic cell vaccines-recent breakthroughs and encouraging clinical results. Front. Immunol. 10:766-766. doi: 10.3389/fimmu. 2019.00766

McCormack, R., de Armas, L. R., Shiratsuchi, M., Ramos, J. E., and Podack, E. R. (2013). Inhibition of intracellular bacterial replication in fibroblasts is dependent on the perforin-like protein (perforin-2) encoded by macrophageexpressed gene 1. J. Innate Immun. 5, 185-194. doi: 10.1159/000345249

Meng, Q., Valentini, D., Rao, M., Dodoo, E., and Maeurer, M. (2018). CMV and EBV targets recognized by tumor-infiltrating B lymphocytes in pancreatic cancer and brain tumors. Sci. Rep. 8:17079. doi: 10.1038/s41598-018-34710-2

Miteva, K., Van Linthout, S., and Tschöpe, C. (2014). Crosstalk between fibroblasts and inflammatory cells. Cardiovasc. Res. 102, 258-269. doi: 10.1093/cvr/cvu062

Mitropoulos, D. N. (2005). Novel insights into the mechanism of action of intravesical immunomodulators. In Vivo 19, 611-621. 
Moores, R. C., Brilha, S., Schutgens, F., Elkington, P. T., and Friedland, J. S. (2017). Epigenetic regulation of matrix metalloproteinase-1 and -3 expression in mycobacterium tuberculosis infection. Front. Immunol. 8:602. doi: 10.3389/ fimmu.2017.00602

Morandi, F., Raffaghello, L., Bianchi, G., Meloni, F., Salis, A., Millo, E., et al. (2008). Immunogenicity of human mesenchymal stem cells in HLA-class I-restricted T-cell responses against viral or tumor-associated antigens. Stem Cells 26, 1275-1287. doi: 10.1634/stemcells.2007-0878

Mourits, V. P., Wijkmans, J. C., Joosten, L. A., and Netea, M. G. (2018). Trained immunity as a novel therapeutic strategy. Curr. Opin. Pharmacol. 41, 52-58. doi: 10.1016/j.coph.2018.04.007

Mukhopadhyay, S., Varin, A., Chen, Y. Y., Liu, B. Y., Tryggvason, K., and Gordon, S. (2011). SR-A/MARCO-mediated ligand delivery enhances intracellular TLR and NLR function, but ligand scavenging from cell surface limits TLR4 response to pathogens. Blood 117, 1319-1328. doi: 10.1182/blood-2010-03276733

Mulder, W. J. M., Ochando, J., Joosten, L. A. B., Fayad, Z. A., and Netea, M. G. (2019). Therapeutic targeting of trained immunity. Nat. Rev. Drug Discov. 18, 553-566. doi: 10.1038/s41573-019-0025-4

Nakayama, M., Takeda, K., Kawano, M., Takai, T., Ishii, N., and Ogasawara, K. (2011). Natural killer (NK)-dendritic cell interactions generate MHC class IIdressed NK cells that regulate CD4+ T cells. Proc. Natl. Acad. Sci. U.S.A. 108, 18360-18365. doi: 10.1073/pnas. 1110584108

Nash, M. J., Frank, D. N., and Friedman, J. E. (2017). Early microbes modify immune system development and metabolic homeostasis-the "Restaurant". Hypothesis Revisited. Front. Endocrinol. 8:349. doi: 10.3389/fendo.2017. 00349

Negi, S., Das, D. K., Pahari, S., Nadeem, S., and Agrewala, J. N. (2019). Potential role of gut microbiota in induction and regulation of innate immune memory. Front. Immunol. 10:2441. doi: 10.3389/fimmu.2019.02441

Netea, M. G., Joosten, L. A. B., and van der Meer, J. W. M. (2017). Hypothesis: stimulation of trained immunity as adjunctive immunotherapy in cancer. J. Leukoc. Biol. 102, 1323-1332. doi: 10.1189/jlb.5RI0217-064RR

Niehrs, A., Garcia-Beltran, W. F., Norman, P. J., Watson, G. M., Hölzemer, A., Chapel, A., et al. (2019). A subset of HLA-DP molecules serve as ligands for the natural cytotoxicity receptor NKp44. Nat. Immunol. 20, 1129-1137. doi: 10.1038/s41590-019-0448-4

Odunsi, K., Qian, F., Matsuzaki, J., Mhawech-Fauceglia, P., Andrews, C., Hoffman, E. W., et al. (2007). Vaccination with an NY-ESO-1 peptide of HLA class I/II specificities induces integrated humoral and $\mathrm{T}$ cell responses in ovarian cancer. Proc. Natl. Acad. Sci. U.S.A. 104, 12837-12842. doi: 10.1073/pnas.07033 42104

Okhrimenko, A., Grun, J. R., Westendorf, K., Fang, Z., Reinke, S., von Roth, P., et al. (2014). Human memory T cells from the bone marrow are resting and maintain long-lasting systemic memory. Proc. Natl. Acad. Sci. U.S.A. 111, 9229-9234. doi: 10.1073/pnas.1318731111

Owens, B. M. J. (2015). Inflammation, innate immunity, and the intestinal stromal cell niche: opportunities and challenges. Front. Immunol. 6:319. doi: 10.3389/ fimmu.2015.00319

Pathria, P., Gotthardt, D., Prchal-Murphy, M., Putz, E. M., Holcmann, M., Schlederer, M., et al. (2015). Myeloid STAT3 promotes formation of colitisassociated colorectal cancer in mice. Oncoimmunology 4:e998529.

Pathria, P., Louis, T. L., and Varner, J. A. (2019). Targeting tumor-associated macrophages in cancer. Trends Immunol. 40, 310-327.

Pedersen, M. B., Danielsen, A. V., Hamilton-Dutoit, S. J., Bendix, K., Norgaard, P., Moller, M. B., et al. (2014). High intratumoral macrophage content is an adverse prognostic feature in anaplastic large cell lymphoma. Histopathology 65 , 490-500. doi: 10.1111/his.12407

Peng, H., Jiang, X., Chen, Y., Sojka, D. K., Wei, H., Gao, X., et al. (2013). Liverresident $\mathrm{NK}$ cells confer adaptive immunity in skin-contact inflammation. J. Clin. Invest. 123, 1444-1456. doi: 10.1172/JCI66381

Petersen, L., Petersen, C. C., Moller-Larsen, A., and Hokland, M. E. (2010). Short-term exposure to human cytomegalovirus-infected fibroblasts induces a proportional increase of active CD94/NKG2A(+) natural killer cells. Hum. Immunol. 71, 29-35. doi: 10.1016/j.humimm.2009.09.355

Pettenati, C., and Ingersoll, M. A. (2018). Mechanisms of BCG immunotherapy and its outlook for bladder cancer. Nat. Rev. Urol. 15, 615-625. doi: 10.1038/ s41585-018-0055-4
Pietras, E. M. (2017). Inflammation: a key regulator of hematopoietic stem cell fate in health and disease. Blood 130, 1693-1698. doi: 10.1182/blood-2017-06780882

Qian, B. Z., and Pollard, J. W. (2010). Macrophage diversity enhances tumor progression and metastasis. Cell 141,39-51. doi: 10.1016/j.cell.2010.03.014

Quintin, J., Saeed, S., Martens, J. H. A., Giamarellos-Bourboulis, E. J., Ifrim, D. C., Logie, C., et al. (2012). Candida albicans infection affords protection against reinfection via functional reprogramming of monocytes. Cell Host Microbe 12, 223-232. doi: 10.1016/j.chom.2012.06.006

Ravi, J., Elbaz, M., Wani, N. A., Nasser, M. W., and Ganju, R. K. (2016). Cannabinoid receptor-2 agonist inhibits macrophage induced EMT in nonsmall cell lung cancer by downregulation of EGFR pathway. Mol. Carcinog. 55, 2063-2076. doi: 10.1002/mc.22451

Riquelme, E., Zhang, Y., Zhang, L., Montiel, M., Zoltan, M., Dong, W., et al. (2019). Tumor microbiome diversity and composition influence pancreatic cancer outcomes. Cell 178:795-806.e12. doi: 10.1016/j.cell.2019. 07.008

Rodriguez, R. M., Suarez-Alvarez, B., and Lopez-Larrea, C. (2019). Therapeutic epigenetic reprogramming of trained immunity in myeloid cells. Trends Immunol. 40, 66-80. doi: 10.1016/j.it.2018.11.006

Romieu-Mourez, R., Francois, M., Boivin, M. N., Stagg, J., and Galipeau, J. (2007). Regulation of MHC class II expression and antigen processing in murine and human mesenchymal stromal cells by IFN-gamma, TGF-beta, and cell density. J. Immunol. 179, 1549-1558. doi: 10.4049/jimmunol.179.3.1549

Rooks, M. G., and Garrett, W. S. (2016). Gut microbiota, metabolites and host immunity. Nat. Rev. Immunol. 16, 341-352. doi: 10.1038/nri.2016.42

Rosario, M., Romee, R., Schneider, S. E., Leong, J. W., Sullivan, R. P., and Fehniger, T. A. (2014). Human cytokine-induced memory-like (CIML) NK cells are active against myeloid leukemia in vitro and vivo. Blood 124, 1117-1117. doi: 10.1182/ blood.v124.21.1117.1117

Rusek, P., Wala, M., Druszczyńska, M., and Fol, M. (2018). Infectious agents as stimuli of trained innate immunity. Int. J. Mol. Sci. 19:456. doi: 10.3390/ ijms 19020456

Saeed, S., Quintin, J., Kerstens, H. H., Rao, N. A., Aghajanirefah, A., Matarese, F., et al. (2014). Epigenetic programming of monocyte-to-macrophage differentiation and trained innate immunity. Science 345:1251086. doi: 10.1126/ science. 1251086

Satoh, T., Takeuchi, O., Vandenbon, A., Yasuda, K., Tanaka, Y., Kumagai, Y., et al. (2010). The Jmjd3-Irf4 axis regulates M2 macrophage polarization and host responses against helminth infection. Nat. Immunol. 11, 936-944. doi: 10.1038/ ni. 1920

Schlums, H., Cichocki, F., Tesi, B., Theorell, J., Beziat, V., Holmes, T. D., et al. (2015). Cytomegalovirus infection drives adaptive epigenetic diversification of NK cells with altered signaling and effector function. Immunity 42, 443-456. doi: 10.1016/j.immuni.2015.02.008

Schrum, J. E., Crabtree, J. N., Dobbs, K. R., Kiritsy, M. C., Reed, G. W., Gazzinelli, R. T., et al. (2018). Cutting edge: plasmodium falciparum induces trained innate immunity. J. Immunol. 200, 1243-1248. doi: 10.4049/jimmunol.1701010

Seya, T., Takeda, Y., and Matsumoto, M. (2015). Tumor vaccines with dsRNA adjuvant ARNAX induces antigen-specific tumor shrinkage without cytokinemia. Oncoimmunology 5:e1043506. doi: 10.1080/2162402x.2015. 1043506

Singh, V., Prakhar, P., Rajmani, R. S., Mahadik, K., Borbora, S. M., and Balaji, K. N. (2017). Histone methyltransferase SET8 epigenetically reprograms host immune responses to assist mycobacterial survival. J. Infect. Dis. 216, 477-488. doi: 10.1093/infdis/jix322

Song, X., Wang, H., Logsdon, C. D., Rashid, A., Fleming, J. B., Abbruzzese, J. L., et al. (2011). Overexpression of receptor tyrosine kinase Axl promotes tumor cell invasion and survival in pancreatic ductal adenocarcinoma. Cancer 117, 734-743. doi: $10.1002 / \mathrm{cncr} .25483$

Sorensen, M. D., Dahlrot, R. H., Boldt, H. B., Hansen, S., and Kristensen, B. W. (2018). Tumour-associated microglia/macrophages predict poor prognosis in high-grade gliomas and correlate with an aggressive tumour subtype. Neuropathol. Appl. Neurobiol. 44, 185-206. doi: 10.1111/nan.12428

Straetemans, T., van Brakel, M., van Steenbergen, S., Broertjes, M., Drexhage, J., Hegmans, J., et al. (2012). TCR gene transfer: MAGE-C2/HLA-A2 and MAGE-A3/HLA-DP4 epitopes as melanoma-specific immune targets. Clin. Dev. Immunol. 2012:586314. doi: 10.1155/2012/586314 
Su, S., Liu, Q., Chen, J., Chen, J., Chen, F., He, C., et al. (2014). A positive feedback loop between mesenchymal-like cancer cells and macrophages is essential to breast cancer metastasis. Cancer Cell. 25, 605-620. doi: 10.1016/j.ccr.2014. 03.021

Sun, J. C., Beilke, J. N., and Lanier, L. L. (2009). Adaptive immune features of natural killer cells. Nature 457, 557-561. doi: 10.1038/nature0 7665

Sun, M., Zhao, W., Xie, Q., Zhan, Y., and Wu, B. (2015). Lentinan reduces tumor progression by enhancing gemcitabine chemotherapy in urothelial bladder cancer. Surg. Oncol. 24, 28-34. doi: 10.1016/j.suronc.2014.11.002

Szebeni, G. J., Vizler, C., Kitajka, K., and Puskas, L. G. (2017). Inflammation and cancer: extra- and intracellular determinants of tumor-associated macrophages as tumor promoters. Media. Inflamm. 2017:9294018. doi: 10.1155/2017/ 9294018

Takeuchi, O., Sato, S., Horiuchi, T., Hoshino, K., Takeda, K., Dong, Z., et al. (2002). Cutting edge: role of Toll-like receptor 1 in mediating immune response to microbial lipoproteins. J. Immunol. 169, 10-14. doi: 10.4049/jimmunol. 169.1.10

Tang, X., Yang, L., Li, Z., Nalin, A. P., Dai, H., Xu, T., et al. (2018). First-inman clinical trial of CAR NK-92 cells: safety test of CD33-CAR NK-92 cells in patients with relapsed and refractory acute myeloid leukemia. Am. J. Cancer Res. 8, 1083-1089.

Tiainen, S., Tumelius, R., Rilla, K., Hamalainen, K., Tammi, M., Tammi, R., et al. (2015). High numbers of macrophages, especially M2-like (CD163-positive), correlate with hyaluronan accumulation and poor outcome in breast cancer. Histopathology 66, 873-883. doi: 10.1111/his.12607

Todoric, J., and Karin, M. (2019). The fire within: cell-autonomous mechanisms in inflammation-driven cancer. Cancer Cell 35, 714-720. doi: 10.1016/j.ccell.2019. 04.001

Tognarelli, S., Wirsching, S., von Metzler, I., Rais, B., Jacobs, B., Serve, H., et al. (2018). Enhancing the activation and releasing the brakes: a double hit strategy to improve NK cell cytotoxicity against multiple myeloma. Front. Immunol. 9:2743. doi: 10.3389/fimmu.2018.02743

Tremaroli, V., and Backhed, F. (2012). Functional interactions between the gut microbiota and host metabolism. Nature 489, 242-249. doi: 10.1038/ nature 11552

van der Heijden, C. D. C. C., Noz, M. P., Joosten, L. A. B., Netea, M. G., Riksen, N. P., and Keating, S. T. (2018). Epigenetics and trained immunity. Antioxidants Redox Signal. 29, 1023-1040. doi: 10.1089/ars.2017.7310

van Montfoort, N., Borst, L., Korrer, M. J., Sluijter, M., Marijt, K. A., Santegoets, S. J., et al. (2018). NKG2A blockade potentiates CD8\&\#xa0;T cell immunity induced by cancer vaccines. Cell 175:1744-1755.e15.

Venza, I., Visalli, M., Fortunato, C., Ruggeri, M., Ratone, S., Caffo, M., et al. (2012). PGE2 induces interleukin-8 derepression in human astrocytoma through coordinated DNA demethylation and histone hyperacetylation. Epigenetics 7, 1315-1330. doi: 10.4161/epi.22446

von Both, U., Berk, M., Agapow, P. M., Wright, J. D., Git, A., Hamilton, M. S., et al. (2018). Mycobacterium tuberculosis exploits a molecular off switch of the immune system for intracellular survival. Sci. Rep. 8:661. doi: 10.1038/s41598017-18528-y

Vono, M., Lin, A., Norrby-Teglund, A., Koup, R. A., Liang, F., and Loré, K. (2017). Neutrophils acquire the capacity for antigen presentation to memory CD4(+) T cells in vitro and ex vivo. Blood 129, 1991-2001. doi: 10.1182/blood-2016-10744441

Voss, J. J. L. P., Ford, C. A., Petrova, S., Melville, L., Paterson, M., Pound, J. D., et al. (2017). Modulation of macrophage antitumor potential by apoptotic lymphoma cells. Cell Death. Differ. 24:971. doi: 10.1038/cdd.2016.132

Walk, J., de Bree, L. C. J., Graumans, W., Stoter, R., van Gemert, G.-J., van de VegteBolmer, M., et al. (2019). Outcomes of controlled human malaria infection after BCG vaccination. Nat. Commun. 10:874. doi: 10.1038/s41467-01908659-3

Wang, H., Li, P., Wang, L., Xia, Z., Huang, H., Lu, Y., et al. (2015). High numbers of CD68+ tumor-associated macrophages correlate with poor prognosis in extranodal NK/T-cell lymphoma, nasal type. Ann. Hematol. 94, 1535-1544. doi: 10.1007/s00277-015-2401-4
Wang, W., Marinis, J. M., Beal, A. M., Savadkar, S., Wu, Y., Khan, M., et al. (2018). RIP1 kinase drives macrophage-mediated adaptive immune tolerance in pancreatic cancer. Cancer Cell 34:e7. doi: 10.1016/j.ccell.2018.10.006

World Health Organization [WHO] (2018). Global Tuberculosis Report. Geneva: World Health Organization.

Wolfers, J., Lozier, A., Raposo, G., Regnault, A., Thery, C., Masurier, C., et al. (2001). Tumor-derived exosomes are a source of shared tumor rejection antigens for CTL cross-priming. Nat. Med. 7, 297-303. doi: 10.1038/85438

Wu, Y., Wu, X., Wu, L., Wang, X., and Liu, Z. (2017). The anticancer functions of RIG-I-like receptors, RIG-I and MDA5, and their applications in cancer therapy. Transl Res. 190, 51-60. doi: 10.1016/j.trsl.2017.08.004

Yamamoto, K., Tateishi, K., Kudo, Y., Sato, T., Yamamoto, S., Miyabayashi, K., et al. (2014). Loss of histone demethylase KDM6B enhances aggressiveness of pancreatic cancer through downregulation of C/EBPalpha. Carcinogenesis 35, 2404-2414. doi: 10.1093/carcin/bgu136

Yan, Q., Sun, L., Zhu, Z., Wang, L., Li, S., and Ye, R. D. (2014). Jmjd3-mediated epigenetic regulation of inflammatory cytokine gene expression in serum amyloid A-stimulated macrophages. Cell. Signal. 26, 1783-1791. doi: 10.1016/ j.cellsig.2014.03.025

Yang, L., Zha, Y., Ding, J., Ye, B., Liu, M., Yan, C., et al. (2019). Histone demethylase KDM6B has an anti-tumorigenic function in neuroblastoma by promoting differentiation. Oncogenesis 8:3. doi: 10.1038/s41389-018-0112-0

Yeo, S. Y., Lee, K. W., Shin, D., An, S., Cho, K. H., and Kim, S. H. (2018). A positive feedback loop bi-stably activates fibroblasts. Nat. Commun. 9:3016. doi: 10.1038/s41467-018-05274-6

Yuan, R., Geng, S., and Li, L. (2016). Molecular mechanisms that underlie the dynamic adaptation of innate monocyte memory to varying stimulant strength of TLR ligands. Front. Immunol. 7:497.

Zhang, W. J., Wang, X. H., Gao, S. T., Chen, C., Xu, X. Y., Sun, Q., et al. (2018). Tumor-associated macrophages correlate with phenomenon of epithelialmesenchymal transition and contribute to poor prognosis in triple-negative breast cancer patients. J. Surg. Res. 222, 93-101. doi: 10.1016/j.jss.2017.09.035

Zhang, Y., Cheng, S., Zhang, M., Zhen, L., Pang, D., Zhang, Q., et al. (2013). Highinfiltration of tumor-associated macrophages predicts unfavorable clinical outcome for node-negative breast cancer. PLoS One 8:e76147. doi: 10.1371/ journal.pone.0076147

Zhou, J., Sheng, J., Fan, Y., Zhu, X., Tao, Q., He, Y., et al. (2018). Association between serum amyloid A levels and cancers: a systematic review and metaanalysis. Postgrad. Med. J. 94, 499-507. doi: 10.1136/postgradmedj-2018136004

Zhou, Y., Hu, Z., Cao, S., Yan, B., Qian, J., and Zhong, H. (2017). Concomitant Mycobacterium tuberculosis infection promotes lung tumor growth through enhancing Treg development. Oncol. Rep. 38, 685-692. doi: 10.3892/or.2017. 5733

Zhu, G., Mei, L., Vishwasrao, H. D., Jacobson, O., Wang, Z., Liu, Y., et al. (2017). Intertwining DNA-RNA nanocapsules loaded with tumor neoantigens as synergistic nanovaccines for cancer immunotherapy. Nat. Commun. 8:1482. doi: 10.1038/s41467-017-01386-7

Ziegler, A., Soldner, C., Lienenklaus, S., Spanier, J., Trittel, S., Riese, P., et al. (2017). A new RNA-based adjuvant enhances virus-specific vaccine responses by locally triggering TLR- and RLH-Dependent effects. J. Immunol. 198, 1595-1605. doi: 10.4049/jimmunol.1601129

Conflict of Interest: The authors declare that the research was conducted in the absence of any commercial or financial relationships that could be construed as a potential conflict of interest.

Copyright (c) 2020 Lérias, de Sousa, Paraschoudi, Martins, Condeço, Figueiredo, Carvalho, Dodoo, Maia, Castillo-Martin, Beltrán, Ligeiro, Rao, Zumla and Maeurer. This is an open-access article distributed under the terms of the Creative Commons Attribution License (CC BY). The use, distribution or reproduction in other forums is permitted, provided the original author(s) and the copyright owner(s) are credited and that the original publication in this journal is cited, in accordance with accepted academic practice. No use, distribution or reproduction is permitted which does not comply with these terms. 